\title{
MILLENNIALS' INTENTION TO WEAR FACE MASKS IN PUBLIC DURING COVID-19 PANDEMIC
}

\author{
Vijay Victor ${ }^{1}$, Sreya $\mathbf{R}^{2}$, Anandakrishnan S Nambiar ${ }^{2}$, Robert Jeyakumar Nathan ${ }^{3}$ \\ ${ }^{1}$ CHRIST (Deemed to be University), ${ }^{2}$ Saintgits Institute of Management, ${ }^{3}$ Multimedia University
}

\begin{abstract}
Many studies in the wake of the COVID 19 pandemic have shown that millennials are reluctant to wear face masks while they are out in public. This poses serious threats to the community, especially to the vulnerable population with comorbidities. Addressing this issue, this study examines the effectiveness of a self-interest statement, collective interest statement, and legal enforcement statement in motivating millennials to wear a mask in public. This study collected data through online survey from Millennials in India and uses a t-test with Welch Approximation to compare the results of the three statements with a control text. The results show collective interest statement was more effective in motivating millennials to wear masks. Reflecting on this finding, the study proposes that authorities and media could frame their advertisements, campaigns and awareness programmes by emphasizing the health of family and friends to motivate millennials to wear face masks in public.
\end{abstract}

KEY WORDS: Face Masks; Reluctance to Wear; COVID-19; Millennials; Collective Interest.

\section{Introduction}

Some of the most relevant problems around the world require an understanding and acceptance of science by the general public, which includes understanding and responding accordingly to a pandemic such as the recent COVID-19 novel coronavirus.

Accordingly, any act or measures to prevent the spread of the disease and avoid these worst-case situations are of utmost importance, and health experts believe that "individual acts or behaviour will play a crucial role to control the spread of the COVID-19" (Anderson et al. 2020). These acts include avoiding public gatherings, cancelling trips and travel plans, maintaining personal hygiene and practising social distance. If steps such as these are practised, experts suggest that number of deaths caused by coronavirus would drop drastically (Ferguson et al., 2020).

The global scientific community is frequently pursuing medical advancements to treat COVID-19, but many researchers point out to the fact that preventive measures adopted also reduce the spread of the disease (Chen et al., 2020; Long et al., 2019; Wang et al., 2020). Such preventive measures include hand washing, social distancing and face mask wearing. A face mask is a protective device that covers the nose, mouth and chin of the wearer. It can be worn either to protect oneself or as a means to protect others. Face masks are used as a protective shield to reduce the transmission of microorganisms. In low-income densely populated nations like India and Pakistan, the incidence of infectious diseases is high and hence, face-masks need to be used to limit the spread of COVID-19 (Jagdhesh et al., 2020). The usage of face mask differs across countries. The western population are reluctant to wear face masks as compared to the people in Asia (Howard, 2020). However, as people move towards their previous lifestyle, increasing number of violations with regard to wearing masks are reported.

The usage of mask serves as a useful example of how collective action among millennials operates in the context of COVID-19. There is a huge outrage that a large group of millennials and Generation- $\mathrm{Z}$ are not hearing the public health cry of concern (Lewis et al., 2020). A study of purchase intention of cigarettes among Millennials were found inelastic with changes in price (Ram et al, 2017). Studies tend to label millennials as impatient, lazy, irrational, entitled and overly social as the reasons for not wearing masks in public (Waljee, Chopra \& Saint, 2018). These stereotyping statements made about millennials feel true in the face of the news articles today about young people's unfavourable response to social distancing norms. The false confidence among young people that they are less susceptible to COVID-19 infection and its effects is one of the factors that hinders our collective effort against the spread of the pandemic.

Given the fact the pandemic will prevail for some more months or even years (Lauerman, 2020), only a behavioural shift among people to accept and adapt to the 'new normal lifestyle' can serve as the best mitigation strategy until an effective and safe vaccine arrives. It is in this regard that the authorities should think of leveraging psychosocial interventions to persuade and motivate people to abide by the new rules and regulations.

This study aims to figure out the potential reasons that could persuade millennials to wear masks while they are out in public. The study mainly employed a conceptual priming strategy that exposed the respondents to stimuli and elicited their reaction. Conceptual priming usually consists of phrases or statements that trigger related memories.

The reaction of the respondents towards a collective interest statement, self-interest statement, legal enforcement statement and a control text were collected and analysed using a $t$ test. By understanding the reaction 
of the respondents towards each of the statements, we can judiciously use our resources and make changes to the existing propagation strategies to coax the millennials into wearing masks.

\section{Literature review}

The Corona Outbreak of 2019 (COVID-19) has created a divide in medical history. With a complete cure of the disease is still at bay, medical professionals assert the usage of face masks and practice of social distancing in order to combat the pandemic (Gharzai et al., 2020). The guidelines with respect to the use of masks have undergone major changes. During the initial stages, usage of masks by the general public was discouraged. However, new guidelines came into force exhorting the usage of non-medical masks as a precautionary measure (Linden \& Savoie, 2020). In one of the first attempts to gauge the behavioural response to the COVID-19 pandemic in the United States, Clements (2020) argued that usage of masks is an emerging phenomenon and can be thought of as a mechanism to prevent infecting others by asymptomatic carriers. For instance, Canadians were found to adopt mask-wearing in public as a means to protect others from COVID-19 rather than as a measure to protect themselves (Linden \& Savoie, 2020).

Wearing a mask may create a new symbolism. During an epidemic, health can be considered as a public good. The pandemic of COVID-19 is of such magnitude that it requires collective action from all members of society. If every member of the society wears a face mask, their cautious action would keep everyone safe and spare the free-ride people the trouble of wearing one. However, more people who choose to be free-ride, the higher the health risk for everyone. This social predicament, related to wearing of face-mask, is based on late the collective action theory (Olson, 1965). The view of collective action in social sciences is that cooperative actions by individuals will benefit everyone in the group; but the individuals with self-interest tend to benefit more by choosing not to cooperate in such actions resulting in a social dilemma (Goetze, 1994; Osaka, 2020). Those incorporating people created the concept of free-riding which simply means the use of 'public goods' by people who are not involved in making them available.

Interventions that encourage wearing of face masks do not have a 'one size fits all' framework and perceptions with respect to face masks are likely to be different between eastern and western populations (Howard, 2020). A solution to the pandemic can be arrived at if policymakers can get people to behave in a way that promotes their common interest even if it comes

at the expense of the individual's interest (Gen Siegal, 2009). Zeng, Chen \& Li (2018) were of the opinion that if people perceived that collective action was related to their own interests they were more likely to participate in the action than those who did not have such perceptions.

Another school of thought puts the onus on legal enforcement measures as a means to curb the pandemic. This finds congruence in the work of Majeed, Seo, Heo \& Lee (2020) who compared the measures taken by the United Kingdom (UK) and South Korea. South Korea put in place a slew of measures, such as remote working, closure of schools and compulsory wearing of face masks. In contrast to that, the UK adopted the policy led by science which heavily relied on mathematical models. South Korea also put in place strict enforcements, such as making violation of quarantine regulations as a criminal offence and resulting in heavy fines or even in extreme cases imprisonment. This stark difference in policy has proven advantageous to South Korea which has successfully controlled the spread of the pandemic.

Chinese Government had taken powerful measures, including declaring a state of a health emergency, prohibition of activities that involved substantial crowd gathering and forced usage of face masks. They utilized the services of policemen and civil servants for inspection of public places, monitoring of traffic and to forcefully stop work if necessary. Even though the pandemic is global, the response to it has been local as pointed out by Tashiro \& Shaw (2020). The specific responses taken by each nation depend on the country's regulations, health ecosystem as well as the culture and behaviour of its citizens. Japan, for instance, provided the legal basis in combating the pandemic by passing certain amendments in its already existing laws. Even in supposedly collectivist societies like Japan, people under the age of 40 were found to be reluctant in wearing masks in order to prevent others from getting infected. However, in those instances, youngsters' motives for using face-masks were based on the self-interest principle (Tashiro \& Shaw, 2020).

Having considered all these options, in this study, the researchers have, thus, chosen the following three interventions: collective interest, legal enforcement and self-interest, in persuading the public to wear face-mask during a pandemic. These interventions are specifically important in the Indian context, which like other Asian countries, is a collectivist society with lesser regard for legal enforcements.

\section{Research Methodology}

This study utilized the experimental design adapted from a study by Linden \& Savoie (2020) who examined the motivations for wearing a mask among the millennials. Two groups with different statements namely; self-interest statement and collective interest statement along with a text for the control group were adopted from the study. The authors developed a new statement namely legal enforcement statement which was also tested in the study.

In order to identify millennials' motivation for wearing masks, a survey experiment was designed and distributed online among millennials in south India. Millennials were selected as they are a dynamic age group who usually show greater peer influence in their decision making and they tend to share their thoughts more actively in impacting each other's decision making (Nathan et al., 2008; Ismail et al, 2015; Mohd Ramli, et al., 2016; Nathan, et al., 2017; Victor et al., 2018). The millennials in this study were selected from 2 large states in India, namely Karnataka and Kerala. A total of 357 responses were collected and 320 were finalised for analysis. The respondents were randomly assigned one of the following texts and were asked to mark their opinion 
based on an 11-point Likert scale where 0 means "no more likely" and 11 means "much more likely".

The collective interest statement (Exp1), self-interest statement (Exp2) and the control text or baseline statement (Exp3) adopted from the study of Linden \& Savoie (2020) are as follows;

Exp1 (Collective Interest) - "Some countries have started asking their citizens to cover their faces when in public in order to avoid potentially transmitting the virus to others with whom they come into contact. The suggestion is that, by wearing a mask, you may be protecting others from infection."

Exp2 (Self-Interest) - "Some countries have started asking their citizens to cover their faces when in public in order to avoid potentially contracting the virus from others with whom they come into contact. The suggestion is that, by wearing a mask, you may be protecting yourself from infection."

Exp3 (Control Text) - "Going forward, how likely are you to voluntarily (i.e., without being required to do so) wear a mask or any sort of protective face covering out in public as a preventative measure against COVID-19?"

The text for legal enforcement statement developed by the authors of this study is as follows;

Exp4 (Legal Text) - Some countries are enforcing the citizens to cover their faces in public places and gatherings, the violators may end up paying an 'extortionate' penalty. The intention is to reduce the spread through legal enforcement.

The control text followed the other three statement texts in the questionnaire. These statements were mainly used to prime the respondents by simply reminding them of the reason for wearing masks.

\section{Data Analysis and Results Discussion}

A two sample t test was used to analyse the difference between the control group or the baseline statement with other statements. Although a contentious debate is still present on whether using parametric tests is appropriate for Likert scale based questions, this study follows the findings of Norman (2010) which states that the assumption of normality for $t$ tests and ANOVA denotes the normal distribution of mean values and not that of the data being used.

Based on the central limit theorem, if the sample size is more than 10 for each group, normal distribution of means may be observed approximately. Furthermore, Glass et al (1972) conducted Monte Carlo simulation tests which confirms that the results of the $\mathrm{F}$ test are robust while analysing Likert scale data. In light of the above mentioned studies, the methodology used to analyse the data was reconfirmed. (Table 1) shows the summary statistics of the 4 statements.
Table 1. Summary Statistics

\begin{tabular}{cccc}
\hline Variable & $\mathbf{N}$ & Mean & Std. Dev. \\
\hline $\begin{array}{c}\text { Exp1 } \\
\text { Collective-Interest }\end{array}$ & 80 & $8.95^{*}$ & 1.48 \\
\hline $\begin{array}{c}\text { Exp2 } \\
\text { Self-Interest }\end{array}$ & 80 & 8.48 & 1.85 \\
\hline $\begin{array}{c}\text { Exp3 } \\
\text { Control-Text } \\
\begin{array}{c}\text { Exp4 } \\
\text { Legal-Text }\end{array}\end{array}$ & 80 & 8.47 & 1.64 \\
\hline *highest mean & 8.36 & 1.89 \\
\hline
\end{tabular}

From (Table 1) it could be seen that Exp4 has the lowest mean value (8.36) and Exp1 has the highest (8.95). The standard deviation for the experiments ranges from 1.48 to 1.89 . The minimum value marked by the respondents for Exp1 is 4, for Exp2 it is 2, for Exp3 and Exp4 it is 1. The maximum value given by the respondents for all experiments is 10 . Table 3 shows the $t$ test results.

The frequency of responses in each experiment is depicted using a bar diagram in (Fig. 1). From the mean statistics and (Fig. 1), it could be inferred that most people intend to wear a mask under all 4 experiments. Nevertheless, the intention of this study is to figure out the statement which is more effective than the baseline statement in coaxing and motivating people to wear masks.

The normal independent $t$ test assumes equal variances of the groups under study. If the assumption of equal variance is violated, $t$ test with unequal variance such as Welch's t test should be used. Levene's test of equality of variance is used to test the assumption of homogeneity of variance. The test results can be found in (Table 2).

The results of Levene's test in (Table 2) show that the $\mathrm{p}$ values for Exp2 and Exp3 are greater than 0.05. But for Exp1 it is below 0.05 implying that the variance is unequal. Hence, Welch's t test which assumes unequal variance was used to test for the differences between the baseline statement and other statements.

The $\mathrm{t}$ test results in (Table 3) shows that all experiments other than Exp1 do not seem to be significant. This indicates that there is a significant difference between the Exp1 and the baseline group (Exp3) implying that the collective interest statement experiment with a higher mean score (8.95) significantly motivate the respondents in Exp1 to wear a mask while they are out in public places. The self interest statement (Exp2) and the legal enforcement statement (Exp4) are not statistically significant while comparing with the baseline statement implying that the probablity of wearing mask in Exp2, Exp4 and the baseline statement is not significantly different.

The results corroborate the findings of the study of Linden \& Savoie (2020) conducted in Canada, where the collective interest statement seemed to be significant in motivating people to wear masks. People are more 
worried about others, perhaps family, relatives and friends than their own health.
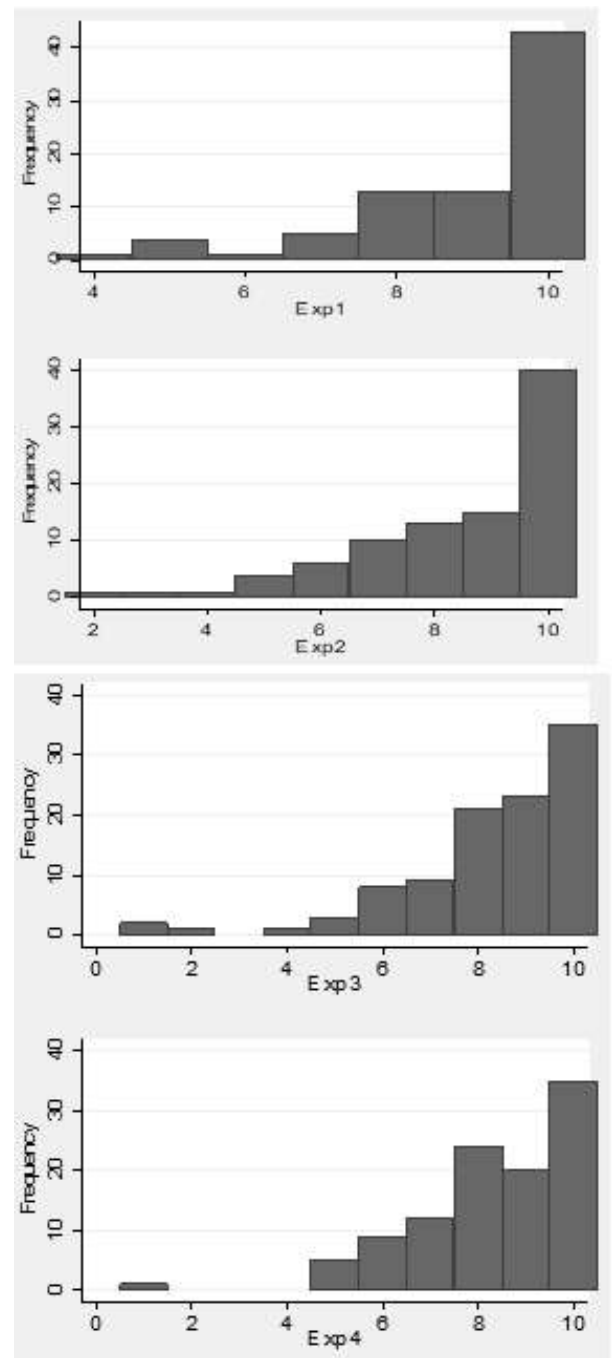

Fig. 1. Frequency of responses

Table 2. Levene's test for equality of variances

\begin{tabular}{|c|c|c|c|c|}
\hline & W0 & df1 & df2 & Sig. \\
\hline Exp3 - Exp1 & 3.25 & 8 & 71 & 0.004 \\
\hline Exp3 - Exp2 & 1.32 & 8 & 71 & 0.053 \\
\hline Exp3 - Exp4 & 1.79 & 8 & 71 & 0.112 \\
\hline
\end{tabular}

Note - Dependent Variable: Exp3

Table 3. T test results with Welch Approximation

\begin{tabular}{|c|c|c|c|c|c|c|}
\hline Var & $\mathbf{N}$ & Mean & Std. Err. & $\begin{array}{c}\text { Std. } \\
\text { Dev. }\end{array}$ & $\mathbf{t}$ & $\begin{array}{c}\text { Pr } \\
(\mathbf{T}>\mathbf{t})\end{array}$ \\
\hline Exp1 & 80 & 8.95 & .165 & 1.48 & 2.1817 & $\mathbf{0 . 0 1 5 3}$ \\
Exp3 & 80 & 8.36 & .212 & 1.89 & & \\
\hline Exp2 & 80 & 8.48 & .207 & 1.85 & 0.4213 & 0.3371 \\
Exp3 & 80 & 8.36 & .212 & 1.89 & & \\
\hline Exp4 & 80 & 8.47 & .183 & 1.64 & 0.4006 & 0.3446 \\
Exp3 & 80 & 8.36 & .212 & 1.89 & & \\
\hline
\end{tabular}

This result provides novel insights to the policy makers and health authorities. Since the results depict that collective interest statement motivates the sample population more than that of the self-interest statement and legal enforcement statement, the advertisements, campaigns and other awareness activities should be framed in such a way that the prime focus is on the collective interest statement. This will help in properly channelising resources which ensures its efficient utilisation that yields positive results.

\section{Recommendations and Conclusion}

This study set forth to examine the motivations of millennials to wear masks in public. The effectiveness of three statements, namely: collective interest statement, self-interest statement and legal enforcement statements were examined to see which statement would have the highest impact towards driving a voluntary mask wearing behaviour against a base statement (control text).

The results indicate that collective interest statement appears to be more effective than the other two statements in driving compliance behaviour among millennials to wear face masks in public. This provides meaningful insights into understanding millennials thinking and decision making behaviour.

The policy implication of this study is that the authorities, policy makers, healthcare authorities and media could emphasise the collective interest of people above other forms of compliance seeking initiative, by emphasizing the health of immediate family members, friends, relatives and people of close contacts while framing advertisements messages, campaigns and awareness activities in order to motivate millennials to wear masks in public places. This would foster greater awareness and invoke a sense of empathy in them and aid in the fight against pandemics like the covid-19.

This study has limitations that could be addressed by future studies conducted in the area. Firstly, the sample size per experiment (for each statement) may be increased in future studies to gather larger respondents from other regions and clusters. More studies should be conducted in different countries and also among various demographics of respondents to ascertain if there are differences among citizens in different age group, including rural and city dwellers which would have higher population density. We also recommend social network analysis study, as it is found effective in recent studies (Lee, et al., 2020) where data on user behaviour during pandemic could be gathered through social media discourse, which could provide richer sentiments about people's mask wearing behaviour.

In the course of carrying out this study, the authors also came to be aware of the cost differences and affordability of face marks for users. Not everyone could afford to purchase single-use face masks while not all governments/countries could provide subsidized face masks for citizens at no cost or affordable prices. These factors could have hampered the decision making of users and this study calls for more national and international support for communities that lack the means to obtain face masks to protect themselves and their community against the pandemic. Comparative study of this nature 
could be carried out between two or more countries and across different continents to give deeper insights on how citizens from different nations are motivated to wear face-masks in the public areas.

\section{References}

Clements, J. M. (2020). Knowledge and Behaviors Toward COVID-19 Among US Residents During the Early Days of the Pandemic: Cross-Sectional Online Questionnaire. JMIR Public Health Surveill, 6(2) doi: 10.2196/19161

Feng, S. (2020). Rational use of face masksin the Covid-19 Pandemic. The LANCET Respiratory Medicine, 8(5) 434436. doi: 10.1016/S2213-2600(20)30134-X

Glass, G. V., Peckham, P. D., \& Sanders, J. R. (1972). Consequences of failure to meet assumptions underlying the fixed effects analyses of variance and covariance. Review of Educational Research, 42(3), 237-288.

Goetze, D. (1994). Comparing prisoner's dilemma, commons dilemma, and public goods provision designs in laboratory experiments. Journal of Conflict Resolution, 38(1), 56-86.

Howard, J., Huang, A., Li, Z., Tufekci, Z., Zdimal, V., HeleneMari van, d. W., Rimoin, A. W. (2020). Face masks against COVID-19: An evidence review. Basel: $M D P I$ AG. doi: http://dx.doi.org/10.20944/preprints202004.0203.v3

Howard, M. C. (2020). Understanding face mask use to prevent coronavirus and other illnesses: Development of a multidimensional face mask perceptions scale. British Journal of Health Psychology. doi: http://dx.doi.org/10.1111/bjhp.12453

Ismail, I.S., Azmi, N.F.A, Nathan, R.J. and Mahadi, M. (2015). Parents' Purchase Behaviour and Buying Decision on Luxury Branded Children's Clothing. Australian Journal of Basic and Applied Sciences, 9(14) 87-92 online: http://www.ajbasweb.com/old/ajbas/2015/Special\%20MPC N\%20LANGKAWI/87-92.pdf

Majeed, A., Seo, Y., Heo, K., \& Lee, D. (2020). Can the UK emulate the south korean approach to covid-19? BMJ, 369 doi: http://dx.doi.org/10.1136/bmj.m2084

Olson, Mancur (1965). Logic of collective action: Public goods and the theory of groups. Cambridge, MA: Harvard University Press.

Osaka, S. (2020). What greater good? COVID is unmasking America's collective action problem. Retrieved from https://grist.org/politics/covid-masks-reveal-americascollective-action-problem

Lauerman, J. (2020). Covid-19 Pandemic Likely to Last Two Years, Report Says, Bloomberg, https://www.bloomberg.com/news/articles/2020-0501/covid-19-pandemic-likely-to-last-two-years-report-says. Accessed on 18/08/2020

Lee, Y.L.; Jung, M.; Nathan, R.J.; Chung, J.-E. (2020) CrossNational Study on the Perception of the Korean Wave and Cultural Hybridity in Indonesia and Malaysia Using Discourse on Social Media. Sustainability, 12, 6072.

Mohd Ramli, S.S, Nathan, R.J. and Liew, T.W. (2016) Adaptation of UTAUT2 Model in Understanding Student's Acceptance of Virtual Learning Agent. Australian Journal of Basic and Applied Sciences, 9(25) 66-71 Online: http://ajbasweb.com/old/ajbas/2015/Special\%20IPN\%20Lan gkawi\%20(Aug)/66-71.pdf

Nathan, R.J., Ibrahim M., \& Adebola, S. (2017). An exploratory study on knowledge sharing behaviors of university students in Singapore. Journal of Advanced and Applied Sciences, 4(5) 56-61 https://doi.org/10.21833/ijaas.2017.05.010

Nathan, R.J., Yeow, P.H.P., \& Murugesan, S. (2008). Key Usability Factors of Service-Oriented Websites for Students: An Empirical Study. Online Information Review, 32(3), doi: 10.1108/14684520810889646

Norman, G. (2010). Likert scales, levels of measurement and the "laws" of statistics. Advances in health sciences education, 15(5), 625-632.

Ram, D, Nathan, R.J., \& Balraj, A. (2017). Purchase Factors for Products with Inelastic Demand: A Study on Tobacco Sector. Journal of Engineering and Applied Sciences, 12(7) 1754-1761. doi: 10.36478/jeasci.2017.1754.1761

Tashiro, A., \& Shaw, R. (2020). COVID-19 Pandemic Response in Japan: What Is behind the Initial Flattening of the Curve? Sustainability, 12(13), 5250 doi:10.3390/su12135250

Van der Linden, C., \& Savoie, J. (2020). Does collective interest or self-interest motivate mask usage as a preventive measure against COVID-19?. Canadian Journal of Political Science/Revue canadienne de science politique, 1-7. https://doi.org/10.1017/S0008423920000475

Victor, V., Thoppan, J.J., Nathan, R.J. \& Farkas M.F. (2018). Factors Influencing Consumer Behavior and Prospective Purchase Decisions in a Dynamic Pricing Environment-An Exploratory Factor Analysis Approach. Social Sciences, 7(9) pp. 153-167.

Zeng, R., Chen, Y., \&amp; Li, H. (2018). Participation in collective action in China: Unfair experience, interests involved, and political efficacy. Social Behavior and Personality: An International Journal, 46(9), 1561-1572. doi:10.2224/sbp.71

Dr. Vijay Victor (Address: Department of Economics, Christ University, Hosur Road, Bengaluru, Karnataka 560029, India; Phone: +36 203857628; Email: vjvictor7@gmail.com) is an assistant professor at the Department of Economics, CHRIST (Deemed to be university), Bangalore, India. He completed his $\mathrm{PhD}$ in Management and Business Administration Sciences from Szent Istvan University, Godollo, Hungary. Vijay's area of interests includes consumer behaviour, online pricing strategies, E-Commerce and industry 4.0 .

Dr. Sreya R (Address: Saintgits Institute of Management, Pathamuttam, Kottayam, Kerala 686532, India: Phone +91 9995998015; Email: sreya.r222@gmail.com) is an Assistant Professor at Saintgits Institute of Management, Kottayam, Kerala, India. She completed her PhD in Management from Kannur University under the Junior Research Fellowship funded by the Govt. of India. Sreya's areas of interest includes Business Analytics, Services Marketing, Consumer behaviour, Organisational Behaviour, Mobile and E-commerce. 
Mr. Ananda Krishnan S Nambiar (Address: Saintgits Institute of Management, Pathamuttam, Kottayam, Kerala 686532, India: Phone +7204625175 ; Email: anandakrishnansnambiar@gmail.com ) is an Assistant Professor at Saintgits Institute of Management, Kottayam, Kerala, India. Anand's area of Interests includes Consumer behaviour, Rural marketing and Pricing Strategies.

Dr. Robert Jeyakumar Nathan (Address: Faculty of Business, Multimedia University, Jalan Ayer Keroh Lama, Melaka, 75450 Malaysia: Phone: +606-2523227; Email: robert.jeyakumar@mmu.edu.my) is the Head of Marketing Degree program and Senior Lecturer with the Faculty of Business, Multimedia University, Malaysia. His research interests include Marketing and Information Technology; Electronic Commerce; Leadership and Organisational Behaviour; Consumer Behaviour, Usability and Ergonomics; Social Media Marketing; and Occupational Safety and Health. 